\title{
Examination of Teachers' Technological Pedagogical Content Knowledge: A Western Regional Perspective of China's Compulsory Education System
}

\author{
Minghan Gou ${ }^{1}$, Dongfang Liu ${ }^{1} \&$ Zhengqing Wang ${ }^{1}$ \\ ${ }^{1}$ Faculty of Education, the Southwest University, Chongqing, China \\ Correspondence: Zhengqing Wang, Faculty of Education, the Southwest University, No. 2 Tiansheng Road, \\ Beibei District, Chongqing, China. E-mail: swuwzq@126.com
}

Received: April 3, 2020 Accepted: May 13, 2020 Online Published: June 19, 2020

doi:10.5539/jel.v9n4p28ＵRL: https://doi.org/10.5539/jel.v9n4p28

\begin{abstract}
Educational technology can provide many advantages for teaching and learning. However, the regional disparity is a well-known result of imbalanced development in China, and the understanding of Western teachers' technological competence is incomplete. This study utilized the Technology, Pedagogy, Content Knowledge Framework (TPACK) in order to examine the overall status and influence of gender toward teachers' technological competence in Western China. The survey method was employed to understand the participants (n $=361$ ) perception of their level of TPACK. The results showed that teachers' pedagogy knowledge and content knowledge were perceived as the highest among the seven types of knowledge examined. All types of technology-related knowledge were perceived as the lowest. Examination of gender influences showed that males perceived significantly higher levels of pedagogy knowledge, technology knowledge, and technological content knowledge. These findings contributed preliminary evidence of the status of teachers' TPACK in Western regions of China and suggested that additional policies and initiatives should be targeted toward improving all teachers' technological competence, particularly among female teachers in the compulsory education system.
\end{abstract}

Keywords: technological pedagogical content knowledge, TPACK, gender, primary education, secondary education, Western China

\section{Introduction}

Technology-supported learning environments can assist learners to develop knowledge and skills more efficiently (Mayer, 2005), as well as in ways that could not be otherwise achieved in more traditional forms of learning environments which do not incorporate the benefits of educational technology (Noroozi, Weinberger, Biemans, Mulder, \& Chizari, 2012; Wu, Lee, Chang, \& Liang, 2013). This understanding of information and communication technology (ICT) applications in educational domains has stimulated a demand for increasing teachers' integration and utilization of technology in primary and secondary education (Deng, Chai, Tsai, \& Lee, 2014; Jimoyiannis, 2010). The technology, pedagogy, content knowledge (TPACK) framework (Mishra \& Koehler, 2006; Cox \& Graham, 2009) is currently one of the most prominent guides for supporting teacher training and assessment, educational research, and policy development related to improving teachers' competence for integrating and utilizing technology in modern classroom settings. The TPACK framework has prominently existed in developed countries; however, ICT applications have only more recently become emphasized in some developing countries, such as in China (Chai, Koh, \& Tsai, 2013). Therefore, to date, comparatively less research has explored the TPACK framework within China, especially among the teacher populations of Western China, which have historically been recognized as being somewhat disadvantaged in comparison to many Eastern regional Chinese contexts.

In China, the tremendous pace of Eastern and urban-prioritized development has led to circumstantial inequality of educational opportunities among students (Golley \& Kong, 2016; Wu, 2013). Circumstantial education inequality refers to participation barriers in the education system that are due to the essence of personal living situations (Gillborn \& Youdell, 1990), such as one's geographic (e.g., Eastern and Western) location of residency. It is well known that many teachers working in Western regions of China are less equipped to appropriately 
utilize technology in their teaching practices (Ministry of Education of China, 2016; Yu, Yu, de Jong, \& Storm, 2015). Such forms of inequality have been recognized as a serious societal issue characterized as the digital divide. That is a circumstance where ICT usage expands education inequality due to ICT applications providing imbalanced developmental advantages among only a portion of the population (Van Dijk, 2005). Recognition of these critical issues has catalyzed policies and initiatives that have prioritized balancing access and utilization of ICT applications within the compulsory nine-year primary and secondary education system in China (Ministry of Education of China, 2014; Ministry of Education of China, 2017a). However, despite much effort toward the remediation of Eastern-Western education inequality in China, little research has examined Western educational contexts to provide an assessment of the initiatives targeting issues of technology integration and utilization.

Without a clear and continuously monitored understanding of the status of Western teachers' technological competence, it is difficult to interpret the effects of professional development initiatives targeted toward easing the digital divide issues that exist within China. Therefore, additional knowledge is needed to assist in informing government policies and contribute data-driven solutions and protocols to address existing equity issues. The present study was designed to examine the status of teachers' TPACK in Western regions of China. The implications of this study contribute knowledge that can practically support in-service teacher education in China, as well as other contexts that possess similar levels of technological and socio-cultural development.

\section{Theoretical and Conceptual Framework}

The theoretical and conceptual framework of the present study is based upon the effectively maintained inequality hypothesis (Lucas, 2001) and the TPACK framework (Mishra \& Koehler, 2006). The effectively maintained inequality hypothesis describes the current status of education equity in China, which generally has shown a slower pace of development in Western regions, in comparison to Eastern regions. Meanwhile, the TPACK framework represents a model for teaching and assessing the appropriate information for integrating and utilizing technology in instructional processes. The related details and interconnections of these theoretical and conceptual components are described in the following sections.

\subsection{The Effectively Maintained Inequality Hypothesis}

As of 2013, reports showed that the national average years of schooling reached a nine-year threshold (National Bureau of Statistics of China, 2016). These statistics suggest that the educational policies that have been encouraging the expansion of access to primary and secondary education have achieved universal student enrollment and that the typical student in China is now participating in the whole nine years of compulsory education. Given that universal enrollment has been achieved, research now suggests that the status of education equity in China can be explained by the effectively maintained inequality hypothesis (Yang \& Wan, 2015). The effectively maintained inequality hypothesis refers to a theoretical assumption that after a society achieves universal enrollment within their compulsory education system, inequity continues to exist within the delivery of different types and qualities of education that are provided to students. Theoretically, this perspective of education equity highlights the rationale of the present study, which aims to assist in understanding the current status of teacher knowledge in Western regions of China. The implications of such knowledge can be used to provide more strategically targeted teacher training programs that aid the reduction of Eastern-Western educational disparities in China.

\subsection{The TPACK Framework}

The TPACK framework was proposed as an expansion of Shulman's (1986) Pedagogical Content Knowledge Framework. Shulman's framework conceptualized the notion that effective teachers were required to possess two different types of knowledge: pedagogical knowledge, which describes competence in one's ability to convey information to others; and content knowledge, which refers to competence in one's ability to understand the subject-specific information which must be conveyed. As shown in Figure 1, Mishra and Koehler (2006) articulated that the emergence of modern educational technologies required a technological perspective of knowledge to be added to Shulman's original framework.

In addition to the three core knowledge domains (pedagogy, content, and technology), Mishra and Koehler's (2006) TPACK framework describes four interrelated sub-domains. These sub-domains are defined as follows: pedagogical content knowledge (PCK), which refers to teachers' understanding of how to adapt teaching strategies to make specific learning contents easier to acquire; technological pedagogical knowledge (TPK), which refers to teachers' understanding of how to use various types of technology to enable teaching approaches; technological content knowledge (TCK), which refers to teachers' understanding of how to use technology to transferring content information; and technological pedagogical content knowledge (TPACK), which refers to teachers' understanding of how to use various types of technology to teach, as well as facilitate students' 
understanding and knowledge creation within a specific educational discipline (Koehler, Mishra, \& Cain, 2013).

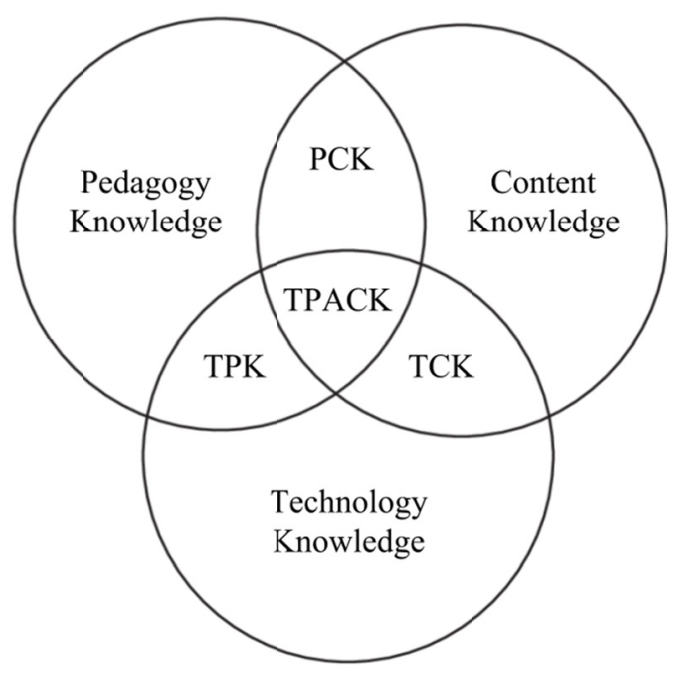

Figure 1. The TPACK framework

Note PCK $=$ Pedagogical content knowledge; TPK $=$ Technological pedagogical knowledge; TCK $=$ Technological content knowledge; TPACK $=$ Technological pedagogical content knowledge.

The TPACK framework provides a helpful guide for teachers to discuss and reflect upon their understanding relating to the knowledge necessary to effectively integrate ICT in their teaching (Archambault \& Crippen, 2009; Schmidt et al., 2009; Voogt, Fisser, Pareja Roblin, Tondeur, \& Van Braak, 2013). Additionally, research has shown that the development of instructors' TPACK can affect instructors' intentions to integrate and continue using technology in their teaching. In contrast, instructors with higher levels of concern regarding their knowledge of teaching may be less inclined to take risks associated with deviations from traditional instruction processes. Thus, it has become quite clear that the TPACK framework is a beneficial resource for assessing and improving the status of teachers' competence in modern classroom contexts.

\subsection{The Present Study}

Based on our review of related studies, the TPACK framework provides an excellent model to guide the development of teachers' technological competence in Western regions of China. However, little is known about the level of teachers' TPACK in Western regions of China. Thus, the following two research questions were proposed to guide the present study:

Research Question 1: What is the overall status of teachers' self-perceived level of TPACK in Western China?

Research Question 2: Does gender influence teachers' self-perceived level of TPACK in Western China?

\section{Methodology}

\subsection{Participants}

The participants $(n=480)$ were purposely selected based on their participation in a teacher education program targeting the Western region of China. As part of China's national training plan, which was jointly established by the Ministry of Education and the Ministry of Finance in 2010, policies mandate that compulsory education teachers receive training at least every five years (Ministry of Education of China, 2017b). These policies were designed to improve the quality of teaching and promote the balanced development of the compulsory education system in China. Responses were received from 410 participants. However, 49 participant responses were identified as being incomplete. Therefore, the sample of the present study included 361 in-service teachers in Western regions of China (Chongqing, Guizhou, Sichuan, and Yunnan). The female-to-male gender ratio was approximately 1:1. Table 1 provides additional details regarding the demographic characteristics of the sample. 
Table 1. Description of sample demographic characteristics.

\begin{tabular}{lll}
\hline Description & Quantity & Percent \\
\hline Gender & 184 & 51 \\
$\quad$ Male & 176 & 49 \\
Female & 1 & 0 \\
$\quad$ Undisclosed & & \\
Age & 36 & 10 \\
21-30 Years old & 147 & 41 \\
31-40 Years old & 165 & 46 \\
41-50 Years old & 13 & 3 \\
Undisclosed & & \\
Experience & 21 & 6 \\
1-5 Years & 50 & 14 \\
6-10 Years & 65 & 18 \\
11-15 Years & 78 & 22 \\
16-20 Years & 147 & 41 \\
$>21$ Years & & \\
Teaching Level & 40 & 11 \\
Grade 1-3 & 101 & 28 \\
Grade 4-6 & 220 & 61 \\
Grade 7-9 & & \\
\hline
\end{tabular}

\subsection{Instrumentation}

The survey utilized in the present study was adapted from existing TPACK instruments (Mishra \& Koehler, 2006; Liu, Zhang, \& Wang, 2015). The complete survey consisted of 42 items and seven scales: Pedagogy Knowledge (7 items), Technology Knowledge (7 items), Content Knowledge (6 items), Technological Content Knowledge (4 items), Pedagogical Content Knowledge (5 items), Technological Pedagogical Knowledge (5 items), and Technological Pedagogical Content Knowledge (7 items). All survey items were measured on a five-point Likert-scale ranging from (1) strongly disagree to (5) strongly agree. The complete list of items used in this study is available in Appendix A.

In order to administer the survey in the participants' native language, the instrument was translated to Mandarin. The translation process first entailed parallel translation (Guillemin, Bombardier, \& Beaton, 1993) by two researchers with committee reconciliation as a means for pre-assessing the translated draft, which means, when there was disagreement regarding the translation of a survey item, the item remained discussed until agreement was reached. Then, the translated survey received bilingual assessment (Harkness \& Schoua-Glusberg, 1998) from a bilingual language specialist. Feedback was collected from the language specialist and used to adjust the wording for several items in order to improve the clarity and readability of the survey.

\subsection{Data Collection and Analysis Procedures}

Before adopting and translating the survey, permission was obtained from the original authors of the instrument. Additionally, before administering the survey to the participants, administrative approval was obtained from the authors' university to conduct the study. All responses were collected voluntarily and anonymously in order to ensure that the participants' maintaining in full control of their personally identifiable information. Data were collected via paper format, then entered into SPSS for data analysis.

\section{Results}

\subsection{Examining the Post-Translation Survey Validity and Reliability of Teacher Responses}

Before interpreting the results, the translated survey used to collect data in the present study must be assessed to confirm the appropriateness of its validity and reliability. Validity should be assessed in terms of convergent and discriminant validity. Convergent validity describes the degree to which items of a scale that theoretically should be related, are in fact related. Convergent validity is evaluated by checking that the average variance extracted (AVE) values are more significant than the recommended threshold of 0.50 (Segars, 1997). As shown in Table 2, the AVE values were observed as ranging from $0.55-0.77$. These results were all above the recommended value of 0.50 , which confirmed that the convergent validity of the scales used was acceptable and suggested that the items of each scale were appropriately correlated to each other.

Discriminant validity describes the extent to which measures of a scale are distinct and uncorrelated. 
Discriminant validity is evaluated by checking that the square root of each AVE value is higher than the inter-construct correlations (Fornell \& Larcker, 1981). As shown in Table 2, this process suggested acceptable discriminant validity for all scales used in the present study. Therefore, it can be assumed that the inferences from the scales used in the present study were appropriate and meaningful.

Reliability describes the extent to which the participants' survey responses are free from error. Reliability is evaluated by checking that the composite reliability (CR) and alpha coefficients are greater than the recommended threshold of 0.70 (Nunnally \& Bernstein, 1994). As shown in Table 2, the CR coefficient values showed a range of $0.88-0.94$, and the alpha coefficient values showed a range of $0.82-0.93$. These results were all above the recommended value of 0.70 , which confirmed that the reliability of participant responses was acceptable. Accordingly, the consistency of the participants' responses was considered to have adequate reliability with relatively little error.

Table 2. Analysis of survey validity and reliability

\begin{tabular}{|c|c|c|c|c|c|c|c|c|c|c|}
\hline & \multicolumn{2}{|c|}{ Reliability } & \multirow{2}{*}{$\begin{array}{l}\text { Convergent Validity } \\
\text { AVE }\end{array}$} & \multicolumn{7}{|c|}{ Discriminant Validity } \\
\hline & $\mathrm{CR}$ & alpha & & $\mathrm{PK}$ & TK & $\mathrm{CK}$ & TCK & PCK & TPK & TPACK \\
\hline PK & .90 & .86 & .55 & .74 & & & & & & \\
\hline $\mathrm{TK}$ & .92 & .90 & .62 & $.31 * *$ & .79 & & & & & \\
\hline CK & .92 & .89 & .65 & $.61 * *$ & $.40 * *$ & .81 & & & & \\
\hline TCK & .88 & .82 & .65 & $.42 * *$ & $.69^{* *}$ & $.55^{* *}$ & .81 & & & \\
\hline PCK & .91 & .88 & .68 & $.60^{* *}$ & $.40 * *$ & $.75 * *$ & $.56^{* *}$ & .83 & & \\
\hline TPK & .91 & .88 & .77 & $.40^{* *}$ & $.59 * *$ & $.51 * *$ & $.75^{* *}$ & $.59^{* *}$ & .88 & \\
\hline TPACK & .94 & .93 & .71 & $.40 * *$ & $.61 * *$ & $.50 * *$ & $.74 * *$ & $.55^{* *}$ & $.80^{* *}$ & .84 \\
\hline
\end{tabular}

Note. $\mathrm{n}=361 ; * * \mathrm{p}<0.01 ; \mathrm{CR}=$ composite reliability; AVE = average variance extracted; Boldface numbers represent the square roots of the AVE; PK = pedagogical knowledge; TK = technology knowledge; $\mathrm{CK}=$ content knowledge; TCK = technology content knowledge; PCK = pedagogical content knowledge; TPK $=$ technological content knowledge; TPACK $=$ technological pedagogical content knowledge.

\subsection{Examining the Overall Status of Teachers' TPACK}

Research question one aimed to understand the overall status of teachers' self-perceived level of TPACK in Western China. Table 3 provides an overview of mean scores and standard deviations (SD) for teachers' responses to the TPACK survey. The results showed teachers' scores were highest for pedagogy knowledge $(\mathrm{M}=$ $4.14, \mathrm{SD}=0.48)$ and content knowledge $(\mathrm{M}=3.98, \mathrm{SD}=0.57)$. Teachers reported the lowest scores for technology knowledge $(\mathrm{M}=3.34, \mathrm{SD}=0.73)$ and technological content knowledge $(\mathrm{M}=3.53, \mathrm{SD}=0.68)$. These findings indicated that roughly $95 \%$ of teachers reported mean pedagogy, content, and technology scores were between $3.18-5.00,2.84-5.00$ and $1.88-4.80$, respectively.

Table 3. Descriptive statistics of the survey

\begin{tabular}{lll}
\hline Scales & Mean & SD \\
\hline Pedagogy Knowledge & 4.14 & 0.48 \\
Technology Knowledge & 3.34 & 0.73 \\
Content Knowledge & 3.98 & 0.57 \\
Technological Content Knowledge & 3.53 & 0.68 \\
Pedagogical Content Knowledge & 3.87 & 0.58 \\
Technological Pedagogical Knowledge & 3.61 & 0.69 \\
Technological Pedagogical Content Knowledge & 3.68 & 0.68 \\
\hline
\end{tabular}

\subsection{Examining Gender Influences}

Research question two aimed to understand whether gender influenced teachers' self-perceived level of TPACK in Western China. As shown in Table 4, a series of t-tests were conducted to analyze teachers' self-perceived TPACK scores by gender. The results showed that males scored higher on three out of the seven scales examined. Males responded significantly higher on pedagogy knowledge $(\mathrm{t}=2.995, \mathrm{p}=0.003)$, technology knowledge $(\mathrm{t}=$ $5.154, \mathrm{p}=0.000)$, and technological content knowledge $(\mathrm{t}=2.974, \mathrm{p}=0.003)$. 
Table 4. Analysis of gender influences

\begin{tabular}{|c|c|c|c|c|c|}
\hline \multirow[t]{2}{*}{ Scales } & Male $(n=184)$ & Female $(n=176)$ & \multirow[t]{2}{*}{$t$} & \multirow{2}{*}{$\begin{array}{l}\text { Sig } \\
\text { (two-tailed) }\end{array}$} & \multirow[t]{2}{*}{ Comparison } \\
\hline & Mean (SD) & Mean (SD) & & & \\
\hline PK & $4.21(0.49)$ & $4.06(0.47)$ & 2.995 & $0.003 * *$ & Male $>$ Female \\
\hline TK & $3.53(0.72)$ & $3.15(0.70)$ & 5.154 & $0.000 * * *$ & Male $>$ Female \\
\hline CK & $4.04(0.60)$ & $3.92(0.54)$ & 2.162 & 0.032 & \\
\hline TCK & $3.63(0.65)$ & $3.42(0.69)$ & 2.974 & $0.003 * *$ & Male $>$ Female \\
\hline PCK & $3.90(0.61)$ & $3.84(0.56)$ & 1.137 & 0.256 & \\
\hline TPK & $3.70(0.70)$ & $3.51(0.68)$ & 2.565 & 0.011 & \\
\hline TPACK & $3.74(0.68)$ & $3.61(0.68)$ & 1.763 & 0.078 & \\
\hline
\end{tabular}

Note. $\mathrm{n}=360 ; * * \mathrm{p}<0.01 ; * * \mathrm{p}<0.001 ; \mathrm{PK}=$ pedagogical knowledge; $\mathrm{TK}=$ technology knowledge; $\mathrm{CK}=$ content knowledge; TCK = technology content knowledge; PCK = pedagogical content knowledge; TPK = technological content knowledge; TPACK $=$ technological pedagogical content knowledge.

\section{Discussion and Conclusion}

Much attention has been focused on the issue of imbalanced development, and the resulting effects on education equity in China (Wu, 2013; Yu et al., 2015). Theoretically, the effectively maintained inequality hypothesis (Lucas, 2001) had been used to describe the current status of services in China's compulsory education system (Yang \& Wan, 2015). Generally speaking, it is clear that the Chinese government has been responding to equity issues and is making progress toward universalizing access to educational ICT resources; however, the more difficult challenge is equalizing the quality of teaching among the different regions of China. The present study utilized the TPACK framework (Mishra \& Koehler, 2006) and was designed to expand understanding of teachers' technological competence in Western China, which provides some preliminary evidence to describe the ways in which technology may be used in the Western regions of China. The results of this study should be used to inform policies and professional development initiatives aimed toward balancing educational opportunities through reducing the digital divide (Van Dijk, 2005) within the compulsory education system.

Overall, teachers' TPACK scores reflected a positive benchmark for teachers' pedagogy and content knowledge. However, the findings showed that a large portion of teachers perceive lower levels of confidence in their abilities to integrate and utilize technology in the classroom. All types of technology-related knowledge (e.g., TK, TPK, TCK, TPACK) were perceived as being lower among teachers, in relation to teachers' pedagogy and content-related knowledge (e.g., PK, CK, PCK). These findings indicate that there continues to be space for improvement among Western teachers. In order to improve teachers' technological competence, it is recommended that additional intervention is necessary, beyond the existing mandated training programs (Ministry of Education of China, 2017b). For example, Western teachers should be encouraged to participate in new organizational processes of professional development and on-the-job learning, which have historically shown benefits among advantaged areas of China. Research has also shown that learning-centered leadership and teacher learning is a good way to improve school quality in China. Additionally, regular teacher collaboration, such as through the participation in teaching and research groups (e.g., Wang, Wang, $\mathrm{Li}, \& \mathrm{Li}, 2017$ ) which can focus on the cultivation of 21st-century digital skills (Van Laar, Van Deursen, Van Dijk, \& De Haan, 2017), is another organizational processes that can encourage the development of teachers' technological competence between teachers' participation in government-mandated training programs.

The results of analyses examining gender influences toward teachers' self-perception of their TPACK showed that males sometimes perceived higher levels of competence than females, particularly concerning pedagogy knowledge, technology knowledge, and technological content knowledge. All other types of knowledge examined showed no statistically significant differences. To the best of our knowledge, these findings contribute the first gender analysis of teachers' self-perceived TPACK levels among a Western teacher sample. Furthermore, it is worth noting that these findings were not aligned with existing research on the general perspective of Chinese teachers, which in contrast, observed significantly stronger beliefs among male teachers regarding content knowledge, as well as significantly stronger beliefs among female teachers regarding pedagogical content knowledge (Liu et al., 2015). These results suggested that among Western regions of China, additional effort should be made to encourage more learning, positive experiencing, and confidence among female teachers. Additionally, due to the inconsistency of results, future research should continue to examine gender influences to expand understanding of gender within this topic of study.

The practical implications of the present study should be interpreted in accordance with the characteristics of some research limitations. First, as a preliminary study aimed to examine teachers residing in the Western region 
of China, this was a quantitative study that relied upon self-report data. Future studies should refine knowledge through the examination of observable data (e.g., Smith, Jones, Gilbert, \& Wieman, 2013), as well as through mixed-method research methodologies that allow the triangulation of data. Second, this study was designed to conceptualize a benchmark for the Western region of China. It is intended that our future studies may utilize comparative or experimental approaches to expand understanding of this vital topic. Finally, the present study broadly explored TPACK in a general sense. Given that research has highlighted needs for more specific analysis of TPACK settings (Voogt et al., 2013), future studies should explore learning environment-specific contexts such as within the smart classroom, or within specific technology-supported instructional approaches such as flipped classroom instruction (Bishop \& Verleger, 2013).

To conclude, this study showcases a benchmark of teacher's perceived technological competence in Western China, an under-researched demographic that has been negatively affected by imbalanced economic development over the past several decades. The findings of this study contribute preliminary evidence that suggests the need for additional and more diverse types of training among Western teachers, particularly females within the compulsory education system. All efforts to improve Western teachers' technological competence represents an important step toward addressing the larger digital divide issue that is maintaining regional disparity and educational inequality in China.

\section{References}

Archambault, L., \& Crippen, K. (2009). Examining TPACK among K-12 online distance educators in the United States. Contemporary Issues in Technology and Teacher Education, 9(1), 71-88. https://www.learntechlib.org/p/29332/

Bishop, J. L., \& Verleger, M. A. (2013, June). The flipped classroom: A survey of the research. Paper presented at 2013 ASEE Annual Conference \& Exposition, Atlanta, Georgia. Retrieved from https://peer.asee.org/22585

Chai, C. S., Koh, J. H. L., \& Tsai, C.-C. (2013). A review of technological pedagogical content knowledge. Journal of Educational Technology \& Society, 16(2), 31-51. https://www.jstor.org/stable/jeductechsoci.16.2.31

Cox, S., \& Graham, C. R. (2009). Diagramming TPACK in practice: using and elaborated model of the TPACK framework to analyze and depict teacher knowledge. TechTrends, 53(5), 60-69. https://doi.org/10.1007/s11528-009-0327-1

Deng, F., Chai, C. S., Tsai, C., \& Lee, M. (2014). The relationships among Chinese practicing teachers' epistemic beliefs, pedagogical beliefs and their beliefs about the use of ICT. Journal of Educational Technology \& Society, 17(2), 245-256. Retrieved from https://www.jstor.org/stable/jeductechsoci.17.2.245

Fornell, C., \& Larcker, D. F. (1981). Evaluating structural equation models with unobservable variables and measurement error. Journal of Marketing Research, 18(1), 39-50. https://doi.org/10.1177/002224378101800104

Gillborn, D., \& Youdell, D. (1990). Rationing education: Policy, practice, reform, and equity. UK: McGraw-Hill Education.

Golley, J., \& Kong, S. T. (2016). Inequality of opportunity in China's educational outcomes. China Economic Review, 51, 116-128. https://doi.org/10.1016/j.chieco.2016.07.002

Guillemin, F., Bombardier, C., \& Beaton, D. (1993). Cross-cultural adaptation of health-related quality of life measures: literature review and proposed guidelines. Journal of Clinical Epidemiology, 46(12), 1417-1432. https://doi.org/10.1016/0895-4356(93)90142-N

Harkness, J. A., \& Schoua-Glusberg, A. (1998). Questionnaires in translation. In J. A. Harkness (Ed.), Cross-cultural survey equivalence (pp. 87-126). Mannheim: Wiley-Interscience. Retrieved from https://nbn-resolving.de/urn:nbn:de:0168-ssoar-49733-1

Jimoyiannis, A. (2010). Designing and implementing an integrated technological pedagogical science knowledge framework for science teachers' professional development. Computers \& Education, 55(3), 1259-1269. https://doi.org/10.1016/j.compedu.2010.05.022

Koehler, M. J., Mishra, P., \& Cain, W. (2013). What is technological pedagogical content knowledge (TPACK)? Journal of Education, 193(3), 13-19. https://doi.org/10.1177/002205741319300303

Liu, Q., Zhang, S., \& Wang, Q. (2015). Surveying Chinese in-service K12 teachers' technology, pedagogy, and 
content knowledge. Journal of Educational Computing Research, 53(1), 55-74. https://doi.org/10.1177/0735633115585929

Lucas, S. R. (2001). Effectively maintained inequality: Education transitions, track mobility, and social background effect. American Journal of Sociology, 106, 1642-1690. https://doi.org/10.1086/321300

Mayer, R. E. (2005). The Cambridge handbook of multimedia learning. New York, NY: Cambridge University Press. https://doi.org/10.1017/CBO9780511816819

Ministry of Education of China. (2014). Ten-year development plan of educational informatization (2011-2020). Retrieved from http://old.moe.gov.cn/publicfiles/business/htmlfiles/moe/s3342/201203/xxgk_133322.html

Ministry of Education of China. (2016). Educational Statistical Yearbook of China. [in Chinese].

Ministry of Education of China. (2017a). Key points of education informatization in 2017. Retrieved from https://www.cac.gov.cn/2017-02/21/c_1120506102.htm

Ministry of Education of China. (2017b). Notice of 2017 national training program for K-9 school teachers. Retrieved from https:/www.moe.gov.cn/srcsite/A10/s7034/201703/t20170314_299563.html

Mishra, P., \& Koehler, M. J. (2006). Technological pedagogical content knowledge: A framework for teacher knowledge. Teachers College Record, 108(6), 1017-1054. https://doi.org/10.1111/j.1467-9620.2006.00684.X

National Bureau of Statistics of China. (2016). China Statistical Yearbook. Retrieved from https://www.stats.gov.cn/enGliSH

Noroozi, O., Weinberger, A., Biemans, H. J. A., Mulder, M., \& Chizari, M. (2012). Augmentation-based computer supported collaborative learning (ABCSCL): A synthesis of 15 years of research. Educational Research Review, 7, 79-106. https://doi.org/10.1016/j.edurev.2011.11.006

Nunnally, J. C., \& Bernstein, I. H. (1994). Psychometric Theory. New York, NY: McGraw-Hill.

Schmidt, D. A., Baran, E., Thompson, A. D., Mishra, P., Koehler, M. J., \& Shin, T. S. (2009). Technological pedagogical content knowledge (TPACK): The development and validation of an assessment instrument for pre-service teachers. Journal of Research on Technology in Education, 42(2), $123-149$. https://doi.org/10.1080/15391523.2009.10782544

Segars, A. H. (1997). Assessing the unidimensionality of measurement: A paradigm and illustration within the context of information systems research. Omega International Journal of Management Science, 25(1), 107121. https://doi.org/10.1016/S0305-0483(96)00051-5

Shulman, L. S. (1986). Those who understand: Knowledge growth in teaching. Educational Researcher, 15(2), 4-14. https://doi.org/10.3102/0013189X015002004

Smith, M. K., Jones, F. H., Gilbert, S. L., \& Wieman, C. E. (2013). The classroom observation protocol for undergraduate STEM (COPUS): A new instrument to characterize university STEM classroom practices. CBE Life Sciences Education, 12(4), 618-627. https://doi.org/10.1187/cbe.13-08-0154

Van Dijk, J. A. G. M. (2005). The deepening divide: Inequality in the information society. Thousand Oaks, CA: Sage publications. https://doi.org/10.4135/9781452229812

Van Laar, E., Van Deursen, A. J. A. M., Van Dijk, J. A. G. M., \& De Haan, J. (2017). The relation between 21st-century skills and digital skills: A systematic literature review. Computers in Human Behavior, 72, 577-588. https://doi.org/10.1016/j.chb.2017.03.010

Voogt, J., Fisser, P., Pareja Roblin, N., Tondeur, J., \& Van Braak, J. (2013). Technological pedagogical content knowledge-A review of the literature. Journal of Computer Assisted Learning, 29(2), 109-121. https://doi.org/10.1111/j.1365-2729.2012.00487.x

Wang, D., Wang, J., Li, H., \& Li, L. (2017). School context and instructional capacity: A comparative study of professional learning communities in rural and urban schools in China. International Journal of Educational Development, 52, 1-9. https://doi.org/10.1016/j.ijedudev.2016.10.009

Wu, H.-K., Lee, S. W.-Y., Chang, H.-Y., \& Liang, J.-C. (2013). Current status, opportunities and challenges of augmented reality in education. Computers \& Education, 62, 41-49. https://doi.org/10.1016/j.compedu.2012.10.024

Wu, Y. (2013). Educational opportunities for rural and urban residents in China, 1978-2008: Inequality and evolution. Social Sciences in China, 34(3), 58-75. https://doi.org/10.1080/02529203.2013.820555 
Yang, B., \& Wan, M. (2015). Changes in urban-rural social structure and distribution of high school educational opportunities-An analysis based on middle school graduation education tracking in Q county, Gansu. Chinese Education \& Society, 48, 433-452. https://doi.org/10.1080/10611932.2015.1119509

Yu, N., Yu, B., de Jong, M., \& Storm, S. (2015). Does inequality in educational attainment matter for China's economic growth? International Journal of Educational Development, 41, 164-173. https://doi.org/10.1016/j.ijedudev.2015.02.008

\section{Appendix A \\ Instrumentation}

\section{Table A1. The TPACK survey}

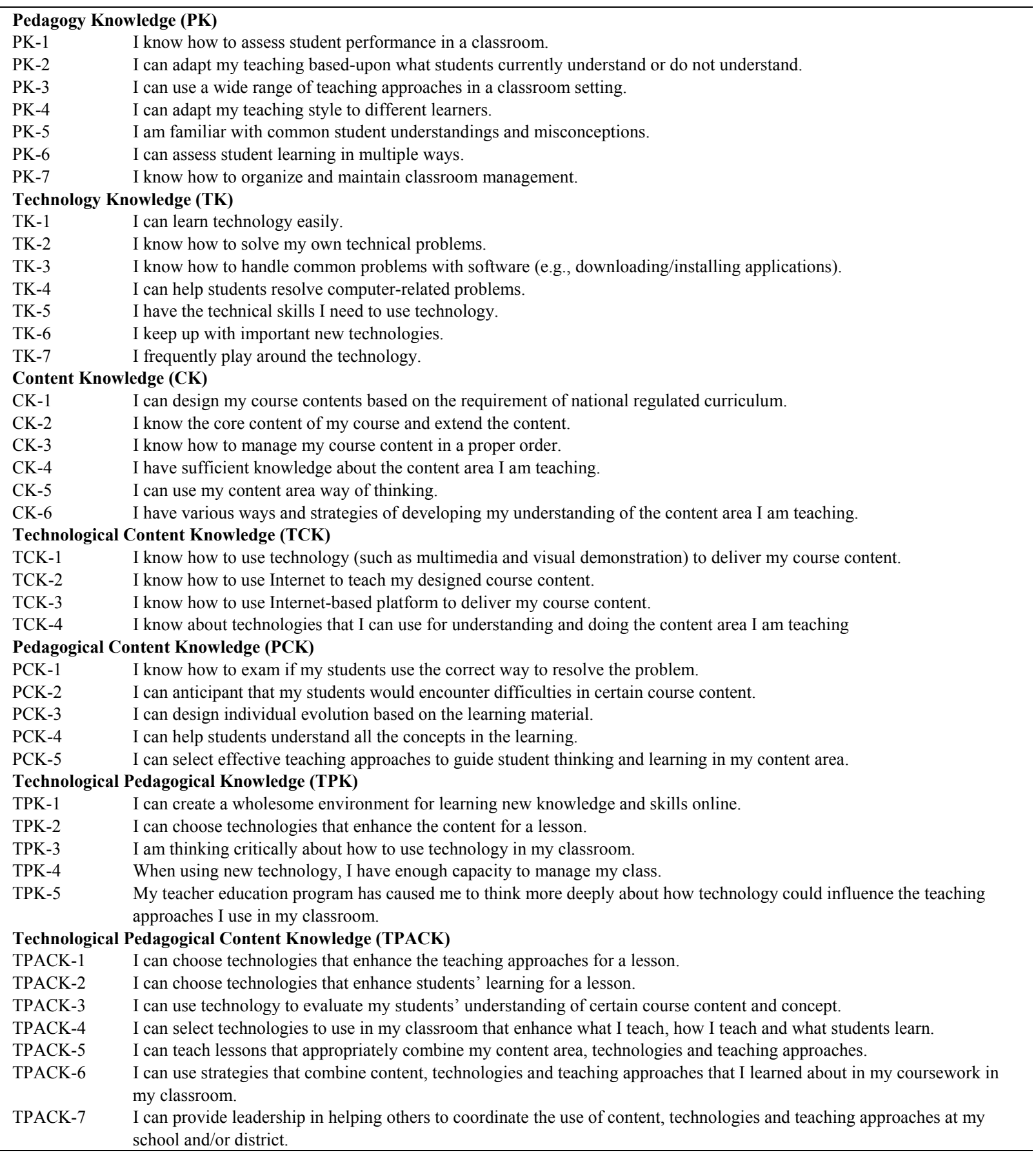




\section{Copyrights}

Copyright for this article is retained by the author, with first publication rights granted to the journal.

This is an open-access article distributed under the terms and conditions of the Creative Commons Attribution license (http://creativecommons.org/licenses/by/4.0/). 